\title{
A RELEVÂNCIA DA BIOECONOMIA PARA O DESENVOLVIMENTO REGIONAL: ESTUDO DE CASO EM UMA EMPRESA DE BIOCOSMÉTICOS DO AMAZONAS
}

The relevance of bioeconomy to regional development: a case study in a biocosmetics company in Amazonas

Andreia Brasil Santos Jannyelle Sousa Rocha Rosana Zau Mafra Márcio Antônio Couto Ferreira 


\title{
A RELEVÂNCIA DA BIOECONOMIA PARA O DESENVOLVIMENTO REGIONAL: ESTUDO DE CASO EM UMA EMPRESA DE BIOCOSMÉTICOS DO AMAZONAS
}

\author{
The relevance of bioeconomy to regional development: a case study in a \\ biocosmetics company in Amazonas
}

\author{
Andreia Brasil Santos \\ Jannyelle Sousa Rocha \\ Rosana Zau Mafra \\ Márcio Antônio Couto Ferreira
}

\section{Grupo de Trabalho (GT): GT7. Desenvolvimento rural, territorial e regional}

\begin{abstract}
Resumo: A bioeconomia surgiu como alternativa para contribuir para o processo de desenvolvimento local e regional dos espaços nos quais se verifica a abundância de recursos naturais. Em alguns contextos, contudo, a adoção da dessa atividade econômica ainda não foi incorporada de forma massiva. Este trabalho teve como objetivo geral abordar a bioeconomia e sua relevância para o Estado Amazonas. Para atingir este objetivo, realizou-se um estudo de caso sendo uma empresa no setor de biocosméticos o objeto de análise deste estudo. A partir da experiência descrita pela empresa, verificou-se que há espaço para o desenvolvimento da bioeconomia no Estado do Amazonas, entretanto, fornecimento das matérias primas amazônicas representam gargalos em termos de regularidade e de qualidade. Estes gargalos precisam ser enfrentados com políticas públicas. Por se tratar de empresa de base biotecnológica, observou-se a importância de parcerias entre startups e institutos de pesquisa.
\end{abstract}

Palavras Chaves: Bioeconomia, Biocosméticos, Bionegócio, Amazonas.

Abstract: The bioeconomy emerged as an alternative to contribute to the process of local and regional development where there is an abundance of natural resources. In some contexts, however, the adoption of this economic activity has not yet been massively incorporated. This work aimed to describe the bioeconomy and its relevance for the State of Amazonas. In order to achieve this objective, a case study was carried out, being a company in the biocosmetics sector the object of analysis of this study. From the experience described by the company, it was found that there is space for the development of the bioeconomy in the State of Amazonas, however, supply of Amazonian raw materials represent bottlenecks in terms of regularity and quality. These bottlenecks need to be addressed with public policies. As it is a biotechnology-based company, the importance of partnerships between startups and research institutes was observed.

Key words: Bioeconomics, Biocosmetics, Biobusiness, Amazonas. 
IGepec, Toledo, V.25, p.91-108, 2021. Edição Especial:58 Congresso da SOBER 


\section{INTRODUÇÃO}

Na região amazônica há uma vasta biodiversidade ainda pouco explorada e estudada, apesar das muitas tentativas de análise. A região é considerada o bioma do Brasil e um dos mais importantes do mundo. Nela encontramos as mais diversas espécies de plantas e variedade de seres vivos presentes na imensidão da floresta amazônica. Esta vasta biodiversidade tem um potencial intrínseco e mercadológico gigante com um celeiro de oportunidades a ser explorada (BOLZANI, 2016).

Em vista disto, tem surgido várias pesquisas sobre como explorar este potencial e preservar, ao mesmo tempo, a biodiversidade nativa minimizando impactos negativos. Desta forma tem-se estudado a biotecnologia atrelada a economia culminando na bioeconomia (DIAS e CARVALHO, 2017; OCDE, 2009). Esta nova área do conhecimento tem potencial para ajudar no desenvolvimento regional e na descoberta de novos recursos provenientes da fauna e flora amazônica, como os alimentos funcionais de frutas totalmente amazônicas e, também, cosméticos, fitoterápicos, entre outros produtos utilizando recursos da própria floresta amazônica.

A bioeconomia ainda é um paradigma a ser respondido. Na literatura há várias definições para o termo bioeconomia. Os principais se referem à bioeconomia como a economia verde, que surgiu a partir da demanda da sociedade moderna, devido a percepção e descoberta da finitude dos recursos naturais, ao esgotamento dos alimentos naturais sem aditivos, da necessidade de fontes de energia renováveis, entre outros recursos (MOREIRA, 2016; BOLZANI, 2016).

Neste contexto, a presente pesquisa considerou como problema de pesquisa a seguinte questão: $O$ setor de biocosméticos pode ser um segmento importante para o desenvolvimento da bioeconomia no estado do Amazonas? Para responder a tal problema, definiu-se como objetivo geral verificar as oportunidades e os desafios de uma empresa de biocosméticos no estado do Amazonas.

Já como objetivos específicos considerou-se: a) sistematizar os aspectos conceituais e práticos sobre biodiversidade e bioeconomia, a partir da literatura disponível; b) realizar um estudo de caso numa empresa de biocosméticos, visando descrever a sua atuação e as estratégias de mercado.

A empresa estudada tem em seus produtos o diferencial em sua matéria prima que é ecologicamente correta e está embutida na sua composição, e também na finalização do produto, buscando ofertar um produto legítimo e com a preocupação sobre a sustentabilidade.

Estudos desta natureza contribuem para o mainstream de pesquisas relacionadas à bioeconomia no Brasil. No mundo contemporâneo tem se falado muito em buscar alternativas sustentáveis e, também, observa-se que houve uma mudança na percepção das pessoas, que cada vez mais se engajam na causa e na luta para preservação do meio ambiente. Consequentemente as pessoas passaram a demandar por produtos livres de química nociva incentivando, assim, o surgimento de um novo mercado.

Neste sentido, a bioeconomia é uma ferramenta que pode ser de grande importância para o desenvolvimento regional, considerando a grande variedade de matérias primas presente na sua biodiversidade, e que se faz de base para um desenvolvimento e crescimento sustentável do Estado do Amazonas. Por outro lado, o mercado de biocosméticos é um segmento que está em constante expansão. 
O trabalho foi estruturado em três seções, além desta introdução e das considerações finais. A primeira apresenta a revisão de literatura, abordando sobre as características da bioeconomia, contendo também sobre a sua origem, os seus aspectos práticos e conceituais. Em seguida discute-se os fitocosméticos e o bionegócio e o seu desenvolvimento no estado do Amazonas. A terceira seção descreve os procedimentos metodológicos da pesquisa. Na quarta seção é apresentada a experiência da empresa pesquisada. Para garantir o sigilo em relação à identificação da empresa conforme acordado com os gestores que concordaram em participar da pesquisa, a empresa será citada como Empresa X.

\section{BIOECONOMIA: ORIGEM, CONCEITO E TRAJETÓRIA}

A Bioeconomia surgiu como uma alternativa de atividade econômica sustentável, devido ao processo da evolução humana e da descoberta da finitude dos recursos naturais. O ser humano, pensando cada vez mais em tal limitação, vem buscando alternativas sustentáveis que não prejudiquem a natureza. Para Moreira (2016, p. 351) a Bioeconomia, "em seu conceito mais amplo, busca diretamente a transformação do conhecimento em desenvolvimento industrial sustentável nas áreas ligadas ao manejo e aproveitamento de recursos biológicos."

Além do problema da finitude dos recursos naturais, tem-se também a problemática do aumento populacional e seu envelhecimento, observando-se, cada vez mais, que nas sociedades desenvolvidas as pessoas vivem além dos sessenta anos de idade. Esse acentuado aumento populacional fez com que houvesse uma necessidade de expansão da oferta de alimentos, saúde, fontes renováveis de energia e água potável (BOLZANI, 2016). Este fenômeno trouxe consciência ao ser humano da escassez dos recursos naturais, e que assim passou a buscar formas sustentáveis de preservar o resto dos recursos naturais originando o surgimento da bioeconomia.

Segundo Trigo et al. (2013) o surgimento da Bioeconomia começou a se desenrolar em países da Europa, Ásia, Estados Unidos, Brasil (com os biocombustíveis) e Costa Rica (com a valorização da biodiversidade). Entretanto, vários autores clássicos já explanavam sobre o assunto no final da década de 1970, a exemplo de Georgescu-Roegen, influenciado por Marx, Schumpeter e Marshall, segundo Dias e Carvalho (2017). Para estes (p.3) "na bioeconomia preconizada por Georgescu-Roegen a natureza atuaria como limitante do processo econômico apesar de não negar a importância do processo tecnológico”.

Outro conceito de bioeconomia disponível na literatura é o da Organização para a Cooperação e Desenvolvimento Econômico (OCDE) que a define como um mundo onde a biotecnologia contribui com uma parcela importante da produção econômica (OCDE, 2009). Ao logo dos anos a visão sobre a bioeconomia foi se transformando, devido aos avanços tecnológicos ou inovações que estão intimamente ligadas com área da biotecnologia.

Para a Comissão Europeia (2012), a bioeconomia envolve três elementos: o conhecimento de biomassa renovável, a biotecnologia e por último, a junção dos dois primeiros elementos formando assim o último elemento. Entretanto, segundo Moreira (2016), a bioeconomia possui as suas diretrizes, baseia-se em pesquisas e também em macro programas de pesquisas focados na produção de alimentos saudáveis, energia sustentável e no uso industrial de matérias primas renováveis. "O conceito de Bioeconomia sempre esteve inserido diretamente na agricultura e nas cadeias agroindustriais alinhadas à produção sustentável” (MOREIRA, 2016, p.351). 
A bioeconomia, portanto, surgiu para solucionar os problemas contemporâneos como atender às demandas decorrentes do aumento populacional e das mudanças climáticas, saúde, e substituição de energia fósseis entre outros.

\subsection{BIOECONOMIA NO BRASIL}

O Brasil é conhecido como um país que possui uma grande biodiversidade. Contando com a maior genética vegetal do mundo com várias espécies de plantas em diferentes biomas sendo portador de uma riqueza imensurável contida em seu bioma com potencial mercadológico gigante, mas pouco explorado. Entretanto, para Bolzani (2016, p.4), "O Brasil, detentor de uma das maiores riquezas naturais do planeta, não pode se orgulhar de uma bioeconomia vigorosa e baseada em inovações a partir da sua rica biodiversidade".

O Brasil passa por um processo de adaptação de forma lenta e possui uma agenda para a bioeconomia, incluída em um planejamento estratégico nacional, com diretrizes bem definidas contendo um direcionamento e ações a serem seguidos propondo assim novos desafios para economia brasileira.

A Bioeconomia apresenta-se aqui como uma nova e promissora vertente econômica, a qual envolve desafios nos ambientes políticos, econômico, cultural e ambiental, abrindo, assim, possibilidades concretas para o aproveitamento sustentável de toda esta biodiversidade. (MOREIRA, 2016, p.352).

Sobretudo o Brasil tem bastante recurso para o desenvolvimento sustentável na área agrícola, no seu plantio e cultivo mais sustentável, no qual nada é jogado fora e tudo é reaproveitado. A área agrícola do país é a que recebe mais destaque no que tange ao aprimoramento da bioeconomia, segundo Silva, Pereira e Martins (2018). Há também o desenvolvimento bioeconômico na área da saúde e no desenvolvimento de fonte de energias renováveis, como os biocombustíveis e biomassa. Assim o país coloca-se em uma situação que o favorece nos mais diversos setores produtivos. Para Moreira (2016, p.352), "o Brasil coloca-se numa situação favorável ao desenvolvimento de uma série de produtos e processos em setores como energia renovável, alimentos funcionais e biofortificados, biopolímeros e cosméticos”.

Observa-se que o Brasil possui grandes oportunidades para a bioeconomia, devido ao seu grande potencial energético. Para Dias e Carvalho (2017, p.1) o país possui vantagens comparativas que podem ser observadas a partir de três aspectos:

(i) possuir a maior diversidade do planeta (ii) possuir os menores custos na produção de biomassa principalmente de cana-de açúcar é (iii) possuir uma agricultura tropical avançada, aplicada na ciência e tecnologia. (DIAS e CARVALHO, 2017, p.1).

Além disso o Brasil possui vantagens comparativas que tem se despontado em suas pesquisas principalmente no que tange à área de alimentos devido a sua vasta biodiversidade. "O Brasil tem sido pioneiro na pesquisa e utilização de produtos agrícolas geneticamente modificados, bem como no desenvolvimento de uma biotecnologia agrícola de ponta”. (DIAS e CARVALHO, 2017, p.19). Em vista disso como o país tem sido pioneiro em pesquisas que desenvolvem a agricultura brasileira, segundo Silva, Pereira e Martins (2018), esta área de pesquisa e enorme, e isto favorece 
o desenvolvimento do dinamismo econômico do agronegócio brasileiro sendo este um importante pilar para o desenvolvimento da bioeconomia no país.

Deste modo a bioeconomia no Brasil se difundiu bastante, tanto na indústria alimentícia como na busca por energias renováveis, ou com o termo chamado de economia verde. O setor de cosméticos também obteve um crescimento bastante significativo, e o país chegou a ocupar, em 2017, a quarta posição no ranking obtendo 6,9\% de participação no mercado mundial ficando atrás somente de Estados Unidos, China e Japão segundo dados da Associação Brasileira de Indústrias de Higiene Pessoal Perfumaria e Cosméticos (ABIHPEC, 2019).

O Brasil é, portanto, um país altamente promissor para a bioeconomia por possuir uma rica biodiversidade e potencial energético para o desenvolvimento socioeconômico, podendo avançar na bioeconomia por possuir vantagem na produção nos mais diversos setores.

\subsection{OS ESFORÇOS DO AMAZONAS NA BIOECONOMIA}

O estado do Amazonas ainda está em fase de desenvolvimento e aprimoramento quando se aborda sobre a bioeconomia, a qual vem se destacando nas discussões e debates. É um tema totalmente novo que vem ganhando mais visibilidade e espaço devido as potencialidades mercadológicas da biodiversidade amazônica.

O aprofundamento da análise sobre a bioeconomia permite identificar uma certa assimetria entre o que é falado em relação a ser uma economia verde e a percepção da realidade. $O$ que se verifica, na prática, é a pouca difusão do potencial mercadológico deste novo segmento que a bioeconomia está criando.

A hipótese de impactos negativos que o crescimento deste novo segmento poderá acarretar à biodiversidade amazônica, ainda gera um certo grau de insegurança com relação aos investimentos em bioeconomia. Será que este novo ramo de negócios contribuirá ainda mais para a expansão do desmatamento ou ainda causará a extinção de espécies plantas nativas da região? Toda essa a análise está no centro dos debates e discursos das políticas governamentais, tendo por objetivo a proteção e preservação da biodiversidade, para promover a sustentabilidade da região Amazônica. Segundo Rodrigues (2018) a Amazônia possui gargalos a serem enfrentados em relação a bioeconomia que ainda tem grandes oportunidades de crescimento, entretanto este setor novo ainda está bastante desfavorecido.

Desta forma, tem-se promovido lentamente este novo segmento, por meio de incentivos à pesquisa e desenvolvimento para a atividade em expansão. A Superintendência da Zona Franca de Manaus (SUFRAMA), no ano de 2018, selecionou uma instituição para gerir projetos de pesquisa e desenvolvimento (P\&D) voltados para área de bioeconomia (IDESAM, 2020). Este programa prioritário da SUFRAMA visa o desenvolvimento de pesquisas na área biotecnológica buscando a exploração, de forma sustentável e econômica, da biodiversidade amazônica.

Em vista disto o esforço do estado em promover a expansão da bioeconomia, ainda caminha a passo lentos, visto que o Amazonas, apesar de seu grande potencial de biodiversidade ainda carece de políticas governamentais voltadas para este novo segmento. "Aproveitar melhor a riqueza da floresta amazônica e aperfeiçoar a legislação para que esses recursos sejam bem utilizados é um passo importantíssimo para inserir o Brasil cada vez na discussão mundial sobre o tema” (RODRIGUES, 2018, p. 22).

Observando os esforços das políticas governamentais do estado, o que se constata é que estes ainda estão voltados para o setor industrial, no qual dispomos do 
modelo Zona Franca, modelo este que desempenha papel importante, impulsionando a maioria dos negócios e investimentos da economia amazonense.

Com a criação de uma nova legislação governamental, seria possível uma expansão mais rápida deste segmento, criando assim um ambiente favorável e atrativo para novos investidores, no qual a região amazônica está no centro de debates e recebe destaque nas discussões internacionais. Desta forma poderia crescer a passos largos e despontar o desenvolvimento regional, fazendo assim frente com outros estados do Brasil.

\section{BIONEGÓCIOS NO AMAZONAS}

O Bionegócio é uma atividade com fins econômicos, desenvolvida por empresas, utilizando-se da biodiversidade. Segundo Sousa (2014) o bionegócio é uma atividade econômica voltada para a extração e comercialização de insumos ou produtos que tenham em sua composição recursos da biodiversidade com valor agregado. Em vista disso o estado do Amazonas possui uma grande gama de oferta desta biodiversidade a ser explorada.

Apesar de existir um mercado promissor, as pequenas empresas de bionegócio ainda se desenvolvem de forma tímida em relação à utilização do recurso da biodiversidade. Segundo Sousa e Figueiredo (2015), o estado do Amazonas ocupa ainda uma posição de fornecedor de commodities ambientais, devido as políticas de desenvolvimento aplicadas no estado que voltam a atenção para fora do estado e se esquecem de sua vasta biodiversidade que ainda não foi totalmente explorada.

Para Frickman e Vasconcellos (2010) o mercado de produtos amazônicos está em constante crescimento representando, assim um segmento novo que pode atrair investimentos para o estado do Amazonas e promover o desenvolvimento regional.

Apesar deste segmento ser atrativo, o processo de desenvolvimento da região amazônica, ainda se utiliza do modelo convencional, que segundo Sousa (2014) baseiase na exploração dos recursos naturais de forma tradicional, gerando perda de grande parte das propriedades naturais durante o processo de extração da matéria-prima.

Esta modalidade de exploração dos recursos naturais, decorre da falta de especialização das comunidades que executam estes processos, e que fazem o manuseio das matérias primas extraídas de forma errada, e que atenda os padrões necessários dos órgãos reguladores.

Deste modo o bionegócio do Amazonas ainda cresce de forma limitada devido à falta de incentivo neste setor, que tem um potencial grandioso, com uma vasta biodiversidade que falta ser explorada, em conjunto com a capacitação dos fornecedores de matérias primas para que se possa alcançar novos patamares onde o Amazonas e um grande celeiro para o desenvolvimento do bionegócio.

A Região Amazônica tem uma vasta biodiversidade. Segundo Herculano et al. (2015) várias são as referências que avaliam positivamente o potencial de aproveitamento diversificado dos recursos florestais da Amazônia brasileira. Segundo Sousa (2016) o Amazonas ainda ocupa o lugar de commodities ambientais, ou seja, vende os recursos amazônicos ainda na sua formar pura, no qual se perde todo o aproveitamento desses recursos.

A partir de estudos feitos com direcionamento biotecnológico, surgiu um novo setor na região, e este busca agregar valor a produtos fabricados que tem por base a biotecnologia empregada de maneira sustentável dando início a um novo segmento na região chamado de bioeconomia. 


\subsection{A PRODUÇÃO DE FITOCOSMÉTICOS NA REGIÃO AMAZÔNICA}

Os recursos da biodiversidade amazônica abriram espaço para um novo mercado, onde a bioeconomia pode agregar valor aos produtos de base biotecnologia.

Os segmentos fitoterápicos \& fitocosméticos constituem setores econômicos de grande relevância para a região amazônica, uma vez que se baseiam no aproveitamento econômico da biodiversidade, mediante o emprego de bases técnico científicas avançadas (SANTANA, 2007, p.1).

O segmento de fitocosméticos na região Amazônica abrange poucas empresas. Tais empresas são de pequeno porte, e encontram dificuldade neste setor que está em expansão. Carvalho (2015, p.24) afirma que há mais de uma década o mercado de fitoterápicos e fitocosméticos "possui políticas estaduais e nacionais específicas para sua reprodução e manutenção e que impactam o uso da natureza, seja como potencialidade ou recurso natural".

As principais dificuldades encontradas no setor de fitocosméticos são a falta de fornecedores de matérias primas, especialmente no que se refere à mão-de-obra especializada. Carvalho (2015) verificou que há uma grande dificuldade por parte das comunidades para entender em que fatia do mercado estão inseridos. Para os camponeses, os fitoterápicos e fitocosméticos são remédios feitos de forma artesanal passados de geração para geração. "Não há um desenvolvimento social, econômico e político para o camponês como sujeito participante e condicionante da base desse mercado" (CARVALHO, 2015, p. 49).

O problema da regularidade no fornecimento dos insumos amazônicos utilizados por empresas deste setor foi apontado por Queiroz e Mafra (2017). Para as pessoas que vivem nessas comunidades, ainda se verifica a dificuldade em entender o interesse do mercado, pois é tão natural a utilização dos recursos da biodiversidade amazônica, para fazer remédio e cuidados para o corpo, cabelo e pele, que não entendem o seu valor e a lucratividade da biodiversidade amazônica para o mercado.

O setor fitocosméticos é um dos mercados mais promissores. Atualmente há uma forte demanda por produtos que não prejudiquem a pele e, que em sua composição não contenha ingredientes tóxicos, que podem trazer malefícios à pele. Este forte crescimento da demanda por produtos orgânicos, naturais e veganos livres de química e não testados em animais, vem da conscientização da população sobre os produtos sintéticos

Segundo Miguel (2007) as cadeias produtivas de cosméticos e fitoterápicos estão expandindo e modernizando empresas e instituições no que se refere as comunidades extrativistas e produtoras seja para a comunidade cientifica e os empreendedores em geral.

A indústria de cosméticos constitui um dos segmentos mais importantes da economia mundial. Segundo dados de 2014, o setor gerou um faturamento mundial de US $\$ 465$ bilhões, com crescimento de $5 \%$ nas vendas de produtos a países emergentes. China e Brasil são os mercados mais promissores (DIAS e CARVALHO, 2017, p.12).

Consequentemente o setor de fitocosméticos na Região Amazônica tem se mostrado também com bastantes oportunidades de crescimento, mesmo com as dificuldades na falta de fornecedores de matérias primas adequadas. Este é um 
segmento que também vem sendo consolidado no Brasil e vem tomando fôlego na economia mundial.

Deste modo, o advento da conscientização da população com a sustentabilidade e os seus vários benefícios, resultou em um aumento da demanda por produtos, que são produzidos de forma sustentável. Esta mudança no gosto do consumidor por produtos livre de substâncias prejudiciais impulsionaram um novo mercado, onde o consumidor passou a demandar produtos chamados de skin care.

\section{PROCEDIMENTOS METODOLÓGICOS}

Esta pesquisa é um estudo de caso que, segundo Yin (2015), é apenas uma das várias formas que se pode fazer pesquisa, tratando-se de uma estratégia que abrange um método com abordagens especificas de coleta e análise de dados. Já para Gil (2002) o estudo de caso necessita de uma análise mais exaustiva e profunda de um objeto ou vários.

O método do estudo de caso adotado é de forma descritiva, no qual se tem objetivo de descrever e estudar o caso. Segundo Yin (2015), o estudo de caso descritivo mostra uma sequência de eventos interpessoais ao longo do tempo, e o que ainda não foi tópico de estudos anteriores e os seus fenômenos. Para o autor, estudos de casos ajudam a examinar os acontecimentos e conta com várias técnicas que podem ser utilizadas, desde pesquisas históricas, análise bibliográfica e documental, livros, revistas cientificas, entrevistas e observações.

O objeto deste estudo de caso foi uma empresa incubada, localizada na cidade de Manaus, pertencente ao segmento de biocosméticos. Por meio deste caso, buscouse verificar a relevância do papel da bioeconomia no Estado do Amazonas, tendo como referência a estratégia adotada pela empresa pesquisada. Através deste método de abordagem foi possível compreender melhor os fenômenos individuais e os processos organizacionais e políticos da sociedade.

A empresa escolhida é uma das poucas empresas da região a atuar no setor de bionegócios. O primeiro contato com a empresa, se deu por meio de mensagem eletrônica, na qual solicitou-se o agendamento da primeira visita às dependências da empresa. Dessa forma, cumpriu-se uma importante orientação de Yin (2015) que é a de que o pesquisador que deve se submeter aos horários e disponibilidade do entrevistado.

Após o agendamento da visita preparou-se um roteiro para a entrevista que foi pautado em perguntas relevantes para a pesquisa. A primeira visita ocorreu no dia 05 de fevereiro de 2019 e os autores foram recebidos pelos gestores da empresa, que permitiram que a entrevista fosse gravada em áudio $\mathrm{O}$ conteúdo da entrevista foi posteriormente transcrito para melhor contribuir com a análise das respostas e dos resultados. Os arquivos desta entrevista estão sob a responsabilidade dos autores da pesquisa.

Considerando a necessidade de aprimoramento das informações e dos dados coletados, foi agendada uma a segunda visita a empresa, que ocorreu no dia 04 de outubro de 2019. Os gestores novamente se colocaram à disposição para responder sobre alguns questionamentos que ainda restavam sobre os dados.

De posse do conteúdo, efetuou-se uma análise do conteúdo transcrito envolvendo raciocínios indutivos, colocando ênfase nas narrativas dos entrevistados e relacionando-as com a literatura acadêmica 


\section{A BIOECONOMIA NO ESTADO DO AMAZONAS SEGUNDO A EXPERIÊNCIA DA EMPRESA $X$}

Esta seção apresenta o resultado da pesquisa de campo, evidenciando as características do caso analisado e, por meio deste, buscando compreender melhor os desafios e oportunidades para o segmento da bioeconomia no estado do Amazonas. considerando a necessidade de manter o sigilo em relação à empresa pesquisada, a mesma será mencionada como sendo Empresa X.

\subsection{CARACTERIZAÇÃO DA EMPRESA ESTUDADA}

A Empresa X foi fundada no ano de 2006 por um pesquisador da área de biotecnologia e recursos naturais que, durante suas pesquisas, descobriu um enorme potencial de um composto encontrado dentro da floresta amazônica. Este composto é extraído de uma planta que é muito utilizada como ornamentação.

A partir desses estudos a Empresa $\mathrm{X}$ firmou parceria com um instituto de pesquisas da área, tornando-se uma empresa incubada deste instituto. Por meio desta parceria, a empresa deu continuidade ao processo de pesquisa aplicada com o objetivo de gerar produtos. Destas pesquisas faziam parte estudantes de pós-graduação (mestrado e doutorado) que utilizavam a infraestrutura da Empresa X, bem como os recursos e aportes necessários para o financiamento da pesquisa.

Algumas dessas pesquisas, desenvolvidas pelos pós-graduandos obtiveram êxito nacional e receberam prêmios, por meio dos quais foi possível a obtenção de mais recursos para a continuidade do processo de desenvolvimento de produtos.

Vale a pena ressaltar que esta modalidade de integração e/ou parceria entre empresas privadas e institutos de pesquisa é uma estratégia bastante salutar e desejável por ambas as partes, uma vez que viabiliza o desenvolvimento de novos produtos, processos ou tecnologias, utilizando o potencial de cada participante da parceria da maneira mais proveitosa possível, com o objetivo de reduzir o hiato existente entre o mercado e academia.

Apesar dos bons resultados observados no período inicial de seu funcionamento, a Empresa X ainda não se encontrava preparada para o mercado. Em 2016, a empresa iniciou uma segunda fase, com o auxílio de um investidor que prospectava alternativas de insumos e matéria prima para o desenvolvimento de um novo negócio no Sul do país. Por já possuir uma experiência prévia no setor de cosméticos e fármacos, este investidor já tinha conhecimento do potencial da biodiversidade amazônica, bem como das possibilidades de diversificar a utilização desta biodiversidade para a produção de cosméticos veganos e naturais, que são muito demandados pelos segmentos do mercado que tem a preocupação com a sustentabilidade. A prospecção o fez chegar até a pesquisa do composto da planta extraída da floresta amazônica, e consequentemente à Empresa X. A partir disso iniciaram as tratativas para a integração deste novo sócio, o que veio a provocar alterações na estratégia de negócios da empresa.

O capital social da Empresa X é composto por recursos dos próprios sócios, e estes não aderiram a nenhum financiamento para a formação deste capital. Um dos sócios realizou o investimento para aquisição da marca e este recurso foi reinvestido na própria empresa, formando o capital de giro necessário para o funcionamento da mesma. Por enquanto, o faturamento obtido com as vendas ainda não foi suficiente 
para garantir o retorno do investimento, mas o tempo de retorno está dentro do estimado nos estudos de viabilidade e no planejamento traçado pela empresa.

O primeiro passo foi registrar a empresa como uma startup e gerar recursos a partir dos produtos resultantes da biodiversidade amazônica, que já haviam sido desenvolvidos anteriormente pela empresa, e que estavam aptos a serem colocados no mercado, passando por uma análise estratégica de demanda. Com este objetivo, viabilizou-se uma modificação na classificação da atividade econômica da empresa, alterando seu registro de uma empresa de pesquisa para uma empresa de indústria e comércio, além de empresa de pesquisa e desenvolvimento. Esta alteração teve como foco manter a pesquisa como área de atuação principal, mas incluir a participação no mercado por meio da oferta de produto final.

Mesmo com a experiência dos anos iniciais em uma incubadora de empresas de pesquisa e desenvolvimento, a nova fase da Empresa $\mathrm{X}$ só entrou em efetivo funcionamento em meados de 2016, devido a todo um processo de regularização pelo qual precisa passar uma empresa de cosméticos para adentrar o mercado. Segundo o responsável, "No setor de cosméticos existe uma intensa legislação visando garantir o padrão de qualidade aceitável pelo órgão regulador e, no caso da [Empresa X], foi necessário cerca de um ano e meio para que todas as licenças fossem obtidas $e$ iniciasse a fabricação de seus produtos”.

Neste aspecto, deve-se salientar a postura proativa que a empresa decidiu adotar. Conhecendo elevado rigor dos órgãos de fiscalização, os gestores tomaram a iniciativa de buscar, antecipadamente, a orientação destes órgãos sobre os procedimentos para a montagem dos laboratórios e demais dependências do setor produtivo, nos termos da legislação em vigor.

Esta proatividade é oriunda de uma observação dos gestores: "a postura mais comum nas novas empresas é primeiramente começar a operar de forma artesanal comprando os insumos e matérias-primas e, posteriormente organizam a estrutura fabril. Procedendo desta maneira, as empresas passam a se preocupar com os aspectos ressaltados pela legislação somente quando o órgão fiscalizador a aborda e evidencia os problemas. A partir disso, passam a buscar as soluções para atender a legislação, porém muitas não conseguem e acabam fechando as portas logo nos anos iniciais devido a não conseguirem atender os padrões de qualidade”.

A Figura 1 resume a trajetória da empresa, considerando uma dimensão temporal.

Figura 1. Diagrama de consolidação da Empresa X

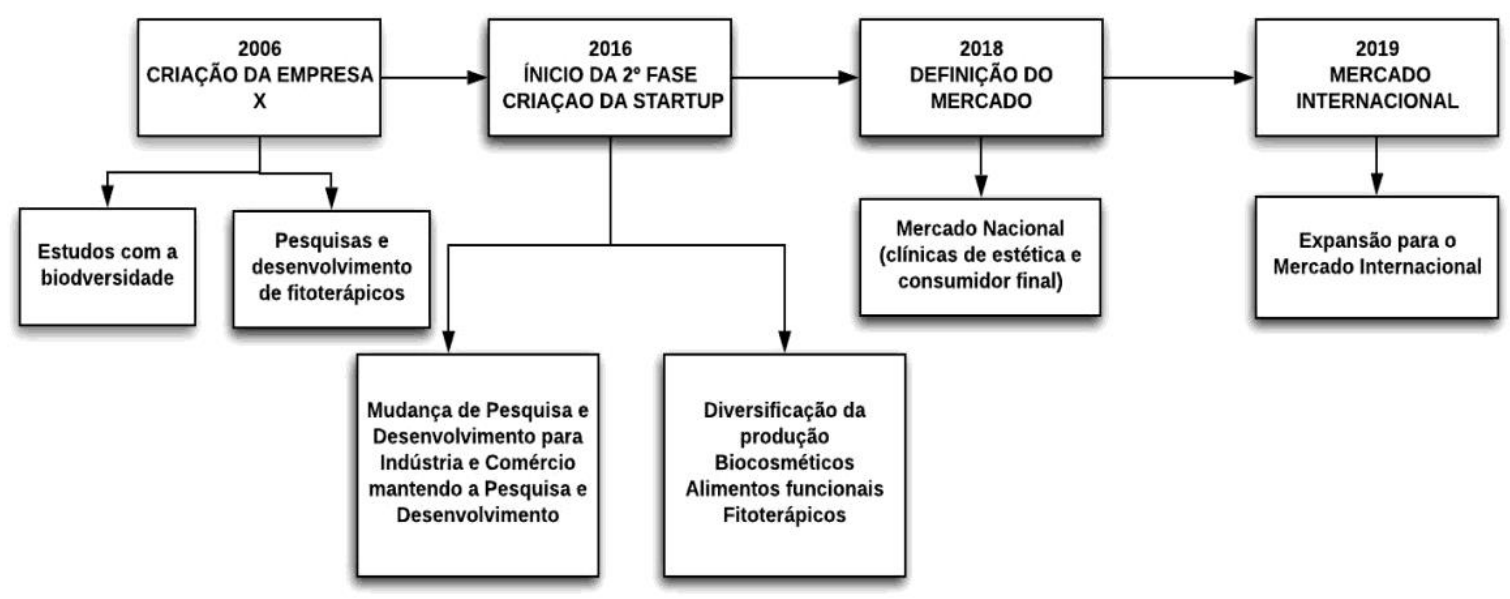

. Fonte: Elaboração própria, com dados obtidos das entrevistas. 
Cumprida esta etapa inicial, o foco da empresa voltou-se para o estudo de mercado de forma mais detalhada, identificando os players do negócio (fornecedores, consumidores e concorrentes) onde se constatou que a empresa tem um grande potencial, mas ainda tem etapas importantes para organizar visando a sua melhor participação no mercado, com por exemplo, o fortalecimento de uma rede de fornecedores que ofertem matéria-prima de qualidade. Este é o aspecto que se configura, no momento atual, a principal necessidade da empresa.

O conceito de bioeconomia está presente na percepção dos gestores da empresa. Para eles a "biotecnologia é uma ferramenta para a prática da bioeconomia, que na sua visão, está relacionada com a participação do homem nos processos que maximizam os efeitos benéficos oriundos dos produtos naturais que são biotecnologicamente ativos". Tal participação é capaz de gerar novos produtos que tem como destino o atendimento às demandas do mercado, mas sem deixar de lado a preocupação com a sustentabilidade e com a manutenção das características naturais do ambiente. Esta percepção se manifesta na visão da Empresa X considerando seu objetivo é levar saúde e beleza através da biodiversidade amazônica, unindo ciência e tecnologia ao conhecimento tradicional.

Os principais insumos demandados pela Empresa X são os óleos, manteigas, extratos, frutas em pó e liofilizadas. Os gestores relatam que no estado do Amazonas não encontraram fornecedores capazes para atender à sua demanda por estes insumos. Este é um problema relatado pelas empresas que atuam na bioindústria amazonense, conforme apontado por Queiroz e Mafra (2017). O atual fornecedor de insumos da Empresa X está no estado do Pará, que já possui empresas qualificadas e com sólida participação no mercado de óleos naturais. A esse respeito, os gestores da Empresa X afirmam que existe uma oportunidade de negócios para os amazonenses. Num primeiro momento, as ações para desenvolver esta oportunidade poderiam ser pauta das políticas públicas, mas é importante que se abra o espaço para tratar a atividade como um segmento de mercado competitivo, capaz de caminhar sozinho, considerando as exigências do mercado. Sem a organização do segmento, as políticas públicas não terão o efeito desejado.

\subsection{A ATUAÇÃO DA EMPRESA X NO MERCADO DE BIOCOSMÉTICOS}

Uma percepção que norteia a atuação dos gestores da Empresa X é a de que $a$ "Amazônia se constitui num grande celeiro de biodiversidade", conforme demonstram a experiência popular e também as pesquisas acadêmicas. Entretanto, esta característica de abundância ainda não consegue ser explorada economicamente, de maneira sustentável, e grande parte da biodiversidade se perde dentro da própria floresta.

A principal preocupação da empresa é fortalecer a atividade econômica relacionada à biodiversidade amazônica, considerando o aspecto da sustentabilidade, sem deixar de lado as demandas do mercado. A atuação da Empresa X no mercado de biocosméticos ocupa um nicho ainda pouco explorado. A maioria das empresas da região Amazônica que atuam neste segmento oferecem produtos tradicionais, fabricados de maneira artesanal e utilizando parebenos e outros produtos químicos. A Empresa X se propõe a oferecer produtos naturais, orgânicos e veganos, sendo a única empresa da Amazônia que oferece ao mercado cosméticos 100\% natural e utilizando matéria prima amazônica/regional. 
Por conta deste novo tipo de demanda os gestores vislumbram transformar esta startup em uma empresa unicórnio no meio da Amazônia. Uma startup unicórnio é uma empresa que consegue alcançar a marca de 1 bilhão de dólares antes de conseguir abrir seu capital na bolsa de valores, ou consegue uma inovação significativa no mercado, capaz de fazê-la se tornar uma figura mitológica assim como o unicórnio, característica esta que no mundo dos negócios é considerado um grande feito (ESPM, 2018).

A Empresa X tem buscado caracterizar uma das suas linhas de produção de óleos vegetais como óleos lídimos (legítimos) da Amazônia. Esta decisão derivou do fato de que várias empresas de todo o Brasil vendem seus produtos utilizando a marca Amazônia, que é, segundo o gestor: "aos olhos do mundo, sinônimo de natureza". Porém, os produtos destas empresas não produzem os efeitos desejados por causa dos processos químicos pelos quais a matéria prima passa até chegar ao produto final. Neste sentido, a Empresa X vem buscando se posicionar no mercado como uma empresa que trabalha com o conceito de respeitar as características naturais do produto, mesmo que para isso tenha que oferecer produtos com prazo de validade menor, observando a sazonalidade das matérias primas, etc.

Outro ramo de atuação da Empresa X, embora secundário, é a produção de alimentos funcionais, utilizando produtos como camu-camu (Myrciaria dubia) e guaraná (Paullinia cupana), por exemplo. Estes produtos também visam atender ao segmento de mercado que busca utilizar bens finais que sejam oriundos de matérias primas naturais e cujo processo produtivo preserve seus atributos originais. Produtos com estas características, segundo os gestores, "oferecem menos efeitos colaterais e seu consumo está em franca expansão no mundo".

Outra questão relacionada aos insumos amazônicos, além da regularidade do fornecimento, é a qualidade. Os gestores declaram que, com o rigor da legislação sanitária é necessário garantir os padrões mínimos de qualidade da matéria prima e das demais etapas do processo produtivo. A experiência da Empresa X indica que há produtores, ou cooperativas de produtores, que ofertam, por exemplo, óleos e essências que são utilizados como matéria prima dos biocosméticos, entretanto, a forma como estes extraem e depois manipulam os produtos da natureza, não se adequam ao padrão exigido pela legislação.

Para exemplificar esta dificuldade, durante a entrevista realizada para a presente pesquisa, os gestores contaram que, entre meados de 2018 e o início de 2019 , divulgaram o interesse da empresa em adquirir óleos de boa qualidade para utilizar em seus processos produtivos. Foram procurados por vários agentes como cooperativas, institutos de pesquisa e organizações não governamentais que desenvolvem trabalhos nas comunidades, porém, a qualidade do óleo ofertado pela grande maioria não atendia aos padrões necessários para o tipo de produto que a Empresa $\mathrm{X}$ deseja produzir.

Considerando este problema, a empresa encontrou parcerias em um instituto que apoia micro e pequenas empresas para tentar reduzir esta dificuldade. Fazendo uma busca em conjunto com esta instituição, identificou-se produtores que desempenham atividade de extração de óleos, mas sem observar o que determina a legislação. Em parceria, a Empresa X e este instituto de apoio às micro e pequenas empresas estão buscando oferecer capacitação a grupos de produtores em comunidades ou cooperativas, visando fortalecer a sua rede de fornecedores.

Contudo outro parceiro da Empresa X neste processo de capacitação dos fornecedores, é uma organização não governamental, sem fins lucrativos. Por meio desta parceria, eles têm buscado o contato com as comunidades tradicionais visando oferecer subsídios que possa qualificar a matéria prima produzida por eles, dando 
viabilidade econômica aos produtos que estão disponíveis na comunidade e abrindo a possibilidade de negociar diretamente com o comprador, eliminando a figura do atravessador

Os processos de estudos e pesquisas continuam fazendo parte do rol de atividades da empresa. Um dos estudos salientados pelos gestores, durante a entrevista, é aquele sobre o óleo de Pracaxi (Pentaclethra macroloba), uma palmeira amazônica que produz um óleo cuja extração é relativamente simples, e que possui propriedades anti-inflamatórias, podendo ser utilizado para cicatrização, como repelente, entre outras finalidades. A Empresa X estima que "um pé desta planta pode gerar receita anual de até $R \$ 5.000,00$ (cinco mil reais)". Entretanto, a falta de difusão do conhecimento sobre as potencialidades deste produto, leva à utilização indevida da planta, por exemplo, para produzir vassouras, cujo valor agregado é muito menor.

Para a Empresa X, esta é uma evidência de que ainda há muito espaço para pesquisa sobre os potenciais da biodiversidade local e, principalmente, quando estas pesquisas tiverem a preocupação com a geração de produtos capazes de produzir retorno econômico.

A empresa ainda possui um laboratório credenciado para emitir laudos sobre a qualidade dos óleos produzidos na Amazônia, óleos estes utilizados como a matéria prima de seus produtos. Esta estrutura tem entre os seus objetivos ajudar as comunidades ribeirinhas do Estado do Amazonas, que extraem os óleos, e aperfeiçoar o seu processo produtivo no sentido de chegar ao insumo com a qualidade e pureza necessários para se tornar matéria prima, considerando os parâmetros de qualidade exigidos pelos produtos que pretendem manter a classificação de $100 \%$ natural. $O$ laboratório de emissão dos laudos não tem fins lucrativos, e foi criado estritamente para aprimorar o processo produtivo seja das comunidades, seja da própria empresa.

\subsection{A ESTRATÉGIA DE NEGÓCIOS ADOTADA PELA EMPRESA}

Apesar da sua origem ligada à produção de fitoterápicos, a Empresa X optou por eleger como seu carro chefe os produtos fitocosméticos, visto que estes apresentam um menor grau de exigências legais e sanitárias e já faziam parte do portfólio de produtos desenvolvidos pelas pesquisas realizadas. A produção dos fitocosméticos poderia garantir uma entrada de recursos mais rápida e viabilizar, posteriormente o retorno à produção dos fitoterápicos.

Os principais produtos da empresa são cosméticos skin care tais como hidratantes, óleo de copaíba (Copaifera langsdorffii), de pracaxi, esfoliantes como máscara hidrantes, entre outros. Os seus principais compradores são as clínicas estéticas, que fazem tratamento de beleza de alto padrão, e farmácias de manipulação. A opção da empresa foi realizar vendas mais técnicas, ou seja, para clientes que valorizem o padrão de qualidade com o qual a Empresa X busca trabalhar e estejam dispostos a pagar o preço do produto, que é mais elevado que o daqueles produtos que utilizam técnicas tradicionais da indústria farmacêutica.

As clínicas de estética, clientes da empresa, trabalham com os produtos da empresa para realizar uma espécie de manutenção dos tratamentos realizados na clínica, pois isto garante melhores resultados para o tratamento. Os produtos são, portanto, oferecidos ao consumidor final pela clínica e não pela Empresa X. A empresa relata que esta modalidade de distribuição dos produtos tem atendido às expectativas de venda. 
Segundo os sócios, esta estratégia de venda nasceu da percepção de que os consumidores têm mudado o padrão de consumo dos bens relacionados à estética corporal. A busca não é somente pela beleza, mas sim por bons resultados estéticos levando em conta a saúde do corpo. É este público que a Empresa X procura atender.

A marca da empresa é de uma planta amazônica cujo fruto brota em meio a floresta dentro de uma vasta biodiversidade amazônica. Assim os produtos da empresa levam como marca este fruto da floresta amazônica.

Em seu site a empresa informa sobre a procedência dos produtos e a rastreabilidade das suas matérias primas, ambos isentos de produtos químico. A Empresa $\mathrm{X}$ também valoriza e incentiva a produção de insumos amazônicos nas comunidades locais gerando assim renda.

Além do site a empresa utiliza-se de redes sociais como o Instagram. As redes sociais no mundo contemporâneo são uma importante ferramenta aliada na divulgação de seus produtos e de sua marca. Em seu Instagram a empresa também fornece informações sobre como obter mais eficiência na utilização de seus produtos de fórmula legítima.

Em relação ao preço dos produtos, é interessante notar que a empresa tem buscado trabalhar com a ideia de agregar valor à sua marca, por meio dos diferenciais que ela oferece ao mercado (qualidade e procedência da matéria prima, certificação dos processos produtivos, manutenção dos princípios ativos da matéria prima, etc.).

Durante a visita à empresa foi possível identificar que, na percepção dos gestores, a empresa vem ocupando um nicho de mercado ainda não explorado, no estado do Amazonas. Eles mencionam que há muitas empresas que fabricam biocosméticos no estado, entretanto estas trabalham com cosméticos naturais, artesanais e convencionais, enquanto a Empresa X direcionou os seus esforços para produtos elaborados com maior rigor de qualidade e obedecendo rígidos padrões de segurança.

Considerando tais características, na metade do ano de 2019 a empresa conseguiu viabilizar a sua participação no mercado internacional, com a linha de fitocosméticos e alimentos funcionais. O processo de certificação visando o mercado árabe já foi obtido, onde iniciaram o processo para a exportação de produtos elaborados, com matéria prima extraída diretamente da Amazônia, e o objetivo da empresa é, a longo prazo, expandir para mais países, como Estados Unidos, China, Israel e outros países do continente europeu.

Esta estratégia evidencia a possibilidade de ocupação de um espaço de mercado que ainda pode ser explorado, entretanto, esta ocupação é muito lenta e extremamente sensível à conjuntura econômica do país. Os entrevistados relataram que entre $2018 \mathrm{e}$ a metade de 2019 a empresa obteve um acréscimo de faturamento, porém, o volume foi abaixo do projetado inicialmente. Entretanto, eles ressaltam que mantém o foco na produção sustentável, buscando a adequação às condições do mercado como um todo, e consideram que a tendência de crescimento da bioeconomia no mundo é uma oportunidade para que a empresa seja uma referência no seu segmento de atuação e possa continuar seu processo de crescimento "remando no mar azul".

\section{CONSIDERAÇÕES FINAIS}

O presente estudo abordou a relevância da bioeconomia para o Estado do Amazonas, que possui a maior parte da biodiversidade brasileira em seu território, com as mais diversas espécies de plantas, a partir de um estudo de caso numa empresa localizada no município de Manaus, que atua no mercado de biocosméticos. 
O estudo, por meio deste estudo de caso, permitiu identificar que ainda há uma grande dificuldade para empreender neste segmento na região amazônica, considerando o baixo número de pesquisas e estudos capazes de conduzirem a elaboração de produtos economicamente viáveis. Permitiu também observar uma expansão lenta, não apenas no setor de biocosméticos mas para a bioeconomia no Estado do Amazonas, apesar da região amazônica ser considerada um celeiro potencial de insumos de interesse comercial. Entretanto há falta de políticas governamentais voltadas para o aprimoramento do setor, refletidas na obtenção de matérias primas e também a falta de fornecedores qualificados que possam atender as empresas de base biotecnológica conforme declarado pelos gestores da empresa estudada. Contudo, mesmo com a falta desses fornecedores na região, o mercado de biocosméticos está em crescente expansão.

Detectou-se também, pelas narrativas dos empresários, que muitos grupos comunitários que participam de cooperativas ou outras formas de associação, não entendem o valor mercadológico das matérias primas retiradas da floresta, e tal desconhecimento leva a situações nas quais se perde o princípio ativo da matéria prima.

O estudo permitiu, por fim, observar pouco investimento na área de bioeconomia no Amazonas, pois a maioria dos esforços das políticas públicas ainda estão direcionados para outros setores industriais, apesar de a bioeconomia se constituir numa atividade que pode contribuir para desenvolvimento regional.

Sugere-se, pelo exposto, que pesquisas futuras ampliem o escopo desta pesquisa, analisando a situação de outras empresas de base biotecnológica, de segmentos distintos e, também os aspectos legais envolvidos na utilização da biodiversidade amazônica, com o intuito de fortalecer a avaliação sobre os impactos que a bioeconomia pode trazer ao desenvolvimento econômico local.

\section{REFERÊNCIAS}

ASSAD, A. L. e AUCÉLIO, J. G. Biotecnologia no Brasil: recentes esforços. In: SILVEIRA, J. M., DAL POZ, M.E. e ASSAD, A L. Biotecnologia e recursos genéticos: desafios e oportunidades para o Brasil. Campinas: Instituto de Economia/Finep, 2004.

ASSOCIAÇÃO BRASILEIRA DE INDÚSTRIAS DE HIGIENE PESSOAL PERFUMARIA E COSMÉTICOS - ABIHPEC. Caderno de Tendências 2o19-2o2o, São Paulo,2019. Disponível em <http://m.sebrae.com.br/Sebrae/Portal\%20Sebrae/Anexos/CADERNO\%20DE\%20 TENDENCIAS\%202019-2020\%20Sebrae\%20Abihpec\%20vs\%20final.pdf $>\quad$ Acesso em 01 Nov de 2019.

BOLZANI, V. da. S. Biodiversidade, bioprospecção e inovação no Brasil. Revista Ciência e Cultura, São Paulo, v.68, n.1, 2016.

CARVALHO, T.P.V de. Mercado de fitoterápicos e fitocosméticos em Manaus (AM). 2015. 190 f. Dissertação (Mestrado em Geografia). Departamento de Geografia. Universidade Federal do Amazonas, Manaus, 2015. 
COMISSÃO EUROPEIA. Communication from the Commission to the European Parliament, the Council, the European Economic and Social Committee and the Committee of the Regions. Strategy for "Innovating for sustainable grow: a bioeconomy for Europe”. Bruxelas, 2012. Disponível em: $<$ http://ec.europa.eu/research/bioeconomy/pdf/official-strategy_en.pdf $>$. Acesso em: 8 Set de 2018.

DIAS, R.F.; CARVALHO, C.A.A. de. Bioeconomia no Brasil e no mundo: panorama atual e perspectivas. Revista Virtual de Química, v.9, n.1, 2017.

ESCOLA SUPERIOR DE PROPAGANDA E MARKETING (ESPM). (Startups) Unicórnio: O que são, o que comem e onde vivem? ESPM, São Paulo. Disponível em: <https://www.espm.br/empreendedorismo/startups-unicornio-o-que-sao-o-quecomem-e-onde-vivem > Acesso em 01 Nov de 2019.

FELIPE, M. S. S. Desenvolvimento Tecnológico e Inovação no Brasil. Desafios na área de biotecnologia. Novos Estudos. 78, Julho, 2007. Disponível em: <http://www.scielo.br/pdf/nec/n78/o2.pdf> Acesso em 10 de abril de 2019.

FRICKMANN, F., VASCONCELLOS, A. Oportunidades para a Inovação e Aproveitamento da Biodiversidade Amazônica em Bases Sustentáveis. Revista T \& C Amazônia, v.8, N.19, 2010.

GEORGESCU-ROEGEN, N. The entropy law and the economic process. Cambridge, MA: Harvard University Press, 1971.

GIL, A.C. Como Elaborar Projetos de Pesquisa 4. ed. São Paulo: Atlas, 2002.

HERCULANO, F.E.B.; PIMENTA, N.L.; PEREIRA, J. O.; VEIGA JR, V. F. da. Ecommercee a utilização da biodiversidade amazônica na indústria de cosméticos. IN: FILHO, G. de. A.; LASMAR, D.J.; HERCULANO, F.E.B.; PIMENTA, N.L. (org). Biotecnologia e Bionegócio no Amazonas. Manaus : EDUA. 2015.

Instituto de Conservação e Desenvolvimento Sustentável da Amazonia (IDESAM). PPBIOECONOMIA - Programa Prioritário de Bioeconomia. Disponível em: https://idesam.org/bioeconomia/ Acesso em março de 2020.

MANFREDI, J.F. O que é Biotecnologia. Revista das Faculdades de Educação, Ciências e Letras e Psicologia Padre Anchieta, v.5, n.10,2003.

MOREIRA, A. M. Bioeconomia: Plataforma Mundial de Inovação e Sustentabilidade nas Cadeias Agroindustriais. Revista Processos Químicos, v. 10, n. 20, p. 351-353, 1 jul. 2016

MIGUEL, L.M. Uso Sustentável da Biodiversidade na Amazônia Brasileira: experiências atuais e perspectivas das bioindústrias de cosméticos e fitoterápicos. 2007. 171 f Dissertação (Mestrado). Departamento de Geografia da Faculdade de Filosofia, Letras e Ciências Humanas da Universidade de São Paulo. São Paulo, 2007.

ORGANIZAÇÃO DE COOPERAÇÃO E DESENVOLVIMENTO ECONÔMICO - OCDE. The bioeconomy to 2030: designing a policy agenda. Paris, France, White House. National Bioeconomy Blueprint; White House, Washington, DC, USA, 2009. 
Disponível em: https://read.oecd-ilibrary.org/economics/the-bioeconomy-to$2030 \quad 9789264056886-e n \#$ page7

QUEIRÓZ, L. A.; MAFRA, R. Z. A comercialização dos produtos naturais da biodiversidade amazônica: características da oferta no comércio varejista em Manaus. In: Estudos da Bioindústria Amazonenses: sustentabilidade, mercado e tecnologia. Manaus: EDUA, 2017. p. 93-112.

RODRIGUES, M. Bioeconomia é a nova fronteira para o futuro da América Latina. Revista Ciência e Cultura, São Paulo, v.70, n.4, 2018.

SANTANA, M. F. E. O perfil da biotecnologia: investimento, recursos humanos e a indústria da biotecnologia. 2004. 239 f. Dissertação (Mestrado) Escola de Química Universidade Federal do Rio de Janeiro, 2004.

SILVA, M.F de. O e.; PEREIRA, F. S.; MATINS, J. V. B. A bioeconomia brasileira em números. Revista BNDES Setorial. n.47• p.277-332, 2018.

SOUSA, K.A. A dinâmica da inovação em bionegócio no Estado do Amazonas. In: XXIV Seminário Nacional de Parque Tecnológico e Incubadoras de Empresas 22 a 26 de setembro de 2014. Belém: Anprotec, 2014. P.25.

SOUSA, K.A.; FIGUEIREDO, G.L.A.de. S. Bionegócios e desenvolvimento alternativo no estado do Amazonas (Brasil). Revista.Hist. Ueg, Anápolis, v.4, n.2, p.139-159, 2015 .

SOUSA, K.A.; SANTOYO, A. H.; MATOS, M. R. de; SILVA, A. C. Bioeconomia na Amazônia: uma análise dos segmentos de fitoterápicos \& fitocosméticos, sob perspectiva da inovação. Revista Uni Evangélica, v.5, n.3, p. 151-171, 2016.

TRIGO E. J.; HENRY, G.; SANDERS, J.; SCHURR, U.; INGELBRECHT, I.; REVEL, C.; SANTANA, C.; ROCHA, P. Towards bioeconomy development in Latin America and the Caribbean, Bioeconomy Working Paper No. 2013-01. ALCUE KBBE FP7 Project No. 264266, 15 p.

VALLE, M.G.; SANTOS, M. S. A biotecnologia como instrumento de desenvolvimento social econômico e social. Revista Univ.Rel.Int, Brasília, v.6, n.1, p.79-89, 2008.

YIN, R. K. Estudo de caso: planejamento e métodos. $5^{\text {a }}$ Ed. Porto Alegre. Editora: Bookmam. 2015.

\section{Sobre os Autores:}

Andreia Brasil Santos. Email: brasiland@ufam.edu.br Jannyelle Sousa Rocha. Email:jannyelle.rocha19@gmail.com Rosana Zau Mafra. Email:rosanazau@gmail.com Marcio Antonio Couto Ferreira. Email:marciocout@yahoo.com.br 